\title{
STATISTICAL ANALYSIS OF EARTHQUAKE CATALOGUE AND MAGNITUDE OF COMPLETENESS FOR NORTHERN AND SOUTHWESTERN PAKISTAN
}

\author{
Shahzada KHURRAM * and Perveiz KHALID \\ Institute of geology, University of the Punjab, Lahore, Pakistan \\ *Corresponding author's e-mail: Khurram.PhD.geo@Pu.edu.pk
}

\begin{tabular}{l} 
ARTICLE INFO \\
\hline Article history: \\
Received 14 September 2021 \\
Accepted 18 November 2021 \\
Available online 2 December 2021 \\
\hline
\end{tabular}

Keywords:

Seismicity rate

Declustering

Aftershocks

Mainshocks

a and $b$-value

Magnitude of completeness

\begin{abstract}
A historical and instrumental earthquake catalogue is prepared for the Northwest Himalayan Fold and Thrust Belt and Makran Subduction Zone Pakistan from 1960 to 2019 with homogenized moment magnitude. The local and some international published sources were utilized for the preparation of catalogue. This earthquake catalogue contained numbers of duplicate, repeated, dependent and independent events. Declustering process was opted to remove the dependent events such as foreshock and aftershock from catalogue to separate the mainshock only in term of distance and time space window. The declustering found 2714 clusters of earthquakes with total of 19512 (57.19\%) events out of 34112. Only cluster events which contained the main shock or independent events were drawn on seismicity map with color identification. Maximum likelihood method was used to compute the value of magnitude of completeness i.e., $M c=3.8$ with estimation of $a$ and $b$-values. Years vise magnitude of completeness was also computed to check the time period variation. The completeness of magnitude for different intervals of time indicates the impartial approximation of previous recorded seismicity. Temporal and spatial maps were also drawn to investigate the slope " $b$ " and rate of productivity " $a$ " in the study region. It is noted that $b$-values varied from 0.2 to 2.0 due to stress and intensive tectonic setting whereas $a$ value increases due to increase the seismicity rate with respect to region. Seismotectonic map was drawn to delineate the major faults, seismicity pattern and tectonic activities. This work further can be used for single value hazard assessment for any region and their response spectra to update buildings and bridges codes.
\end{abstract}

\section{INTRODUCTION}

Earthquake is one the forceful catastrophe among the all-natural disasters. In the field of geophysics, seismology and civil engineering, estimation of peak ground acceleration is the necessary for seismic hazard assessment. Crustal deformation can be estimated through the ground motion intensity (Mignan and Woessner, 2012). Earthquake clusters are the package of similar seismic events and their magnitude with respect to their specific time period (Stiphout et al., 2012). These seismic clusters generate due to stress and strain behavior in surrounding fault systems (Zaliapin et al., 2008). This phenomenon causes to produce the rupture on the surface which is the source of another earthquake either it is of high or low intensity. A comprehensive erthquake catalogue is the main directory that contained very useful information including waveform duration and epicentral locations (Stiphout et al., 2012). Each event of earthquake contained epicenter location, time, depth, magnitude in time scale data. To observe and analyze the ground motion and their respective parameters, past chain of seismicity with their characteristics is necessary (Sherif, 2016). The seismicity indicates earthquake occurring process due to different tectonic and environmental phenomena in time and space window (Pisarenko and Rodkin, 2019).

Last two decades this natural disaster increased due to various factors such as increasing temperature, velocity of tectonic plates and some anthropogenic seismic activities (Ray et al., 2019). The earthquake triggering forces enhance this natural disaster by means of hidden forces inside the earth like convection cell in mantle, volcanic eruption and plate movement. For the measurement of this vulnerability the seismic hazard assessment (SHA) is an important tool to calculate the expected acceleration of ground motion for site (Muzzaffar and Kumar, 2018). The SHA is performed on the basis of well-defined and complete comprehensive earthquake catalogue which consists of the numbers of mainshock only (Console et al., 2010) but researchers preferred to use catalogue including aftershocks and foreshocks as well. This will give the reliable value of peak ground acceleration. According to Stiphout et al. (2012) earthquake catalogue consists of the dependent and independent events. The proportioning of these types of event called declustering. Stiphout et al. (2012) also explicate the term declustering of the seismic catalogue as the independent events that are 


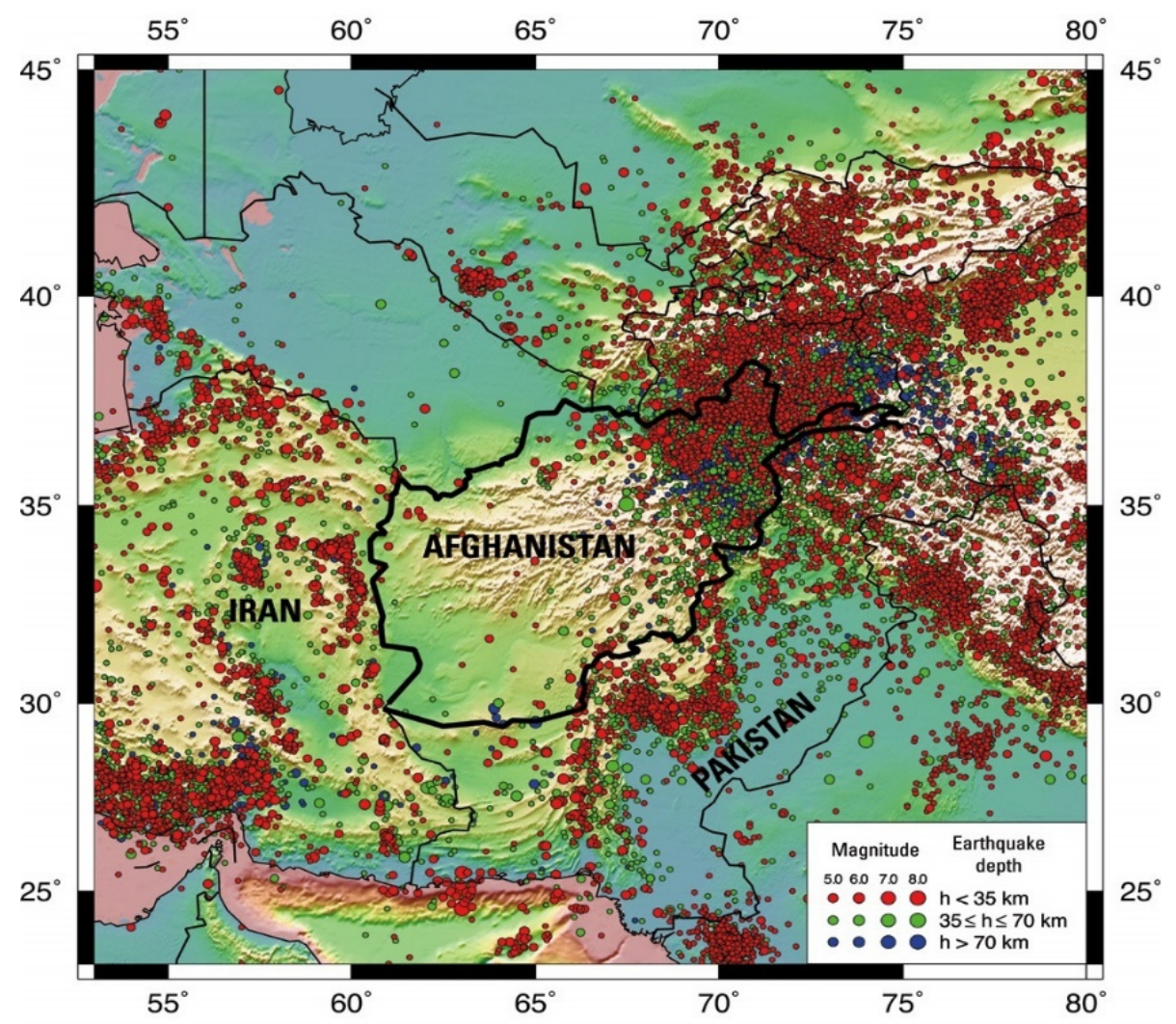

Fig. 1 Seismicity map of Pakistan and its surrounding region showing all seismic events of different magnitudes.

characterize by background earthquake, mainshocks or parent earthquake foreshocks. Braunmiller et al. (2005) also explained catalogue property that magnitude converting scale, removal of duplicate events, identification of mainshocks, aftershocks and foreshocks using statistical analysis of earthquake data. Larger magnitude seismic event generates a massive destruction on large scale and this can be partially reduced before construction, determine the suitable value peak ground acceleration after utilizing complete and magnified earthquake catalogue (Ambraseys, 1971). The annual rate of seismicity of any region is based on the earthquake catalogue and number of earthquakes per year can be estimates using frequency magnitude relation (Gutenberg Richter law) associated with their $a$ and $b$-values of specific region (Gutenberg and Richter, 1954, 1956a, 1956b). Different researchers proposed different procedures for declustering of earthquake catalogues (Knopoff and Gadner, 1972; Gardner and Knopoff, 1974; Reasenberg, 1985; Uhrhammer, 1986; Grunthal et al., 2009; Wiemer, 2001). A comprehensive detailed catalogue is the key to interpret the earthquake activity rate and analysis of occurrence and reoccurrence in the form of time series (Gupta et al., 2012).

Recently, Taroni and Akinci (2021) investigated the performance of two different declustering procedures applied on the Italian Instrumental Catalogue and studied the impact of declustering on the $b$-value estimation and seismic hazard analysis. They observed that the hazard estimated from the declustered catalogue was smaller than the hazard estimated from the complete catalogue. According to this study removing the aftershock or foreshocks from the main catalogues leads to underestimation of the annual rates of the events and consequently associates with low seismic hazard as indicated by several studies. To generate earthquake catalogue for declustering it is very useful to select the suitable algorithm. Cluster catalogue constituted many raw information and duplication of a lot of seismic events. History of devastating earthquake event describes the earth orientation and process which related to the ground motion.

Due to presence of plate junctions and active tectonics Pakistan is situated in intermediate to high seismicity zone (Khurram et al., 2021). The relatively high seismicity rate in the NW Himalayan Fold and Thrust Belt and Makran Subduction Zone of Pakistan is due to active tectonics movements. A large numbers of seismic events of different magnitudes can be seen in northern parts at Pak-Afghan border covered in Hindu Kush, Himalayan and Karakorum region. Majority of the earthquakes were concentrated at shallow depth $\leq 70 \mathrm{~km}$ whereas some are between $70 \mathrm{~km}-250 \mathrm{~km}$. Convergent plate boundary generates numerous thrust fault system in this region. The composite earthquake catalogue was organized from 1960 - 2019 containing spatial-temporal information of each seismic event. This catalogue evenly distributed on the map showing the seismicity of the region bounded by Pakistan and surrounding (Fig. 1). 


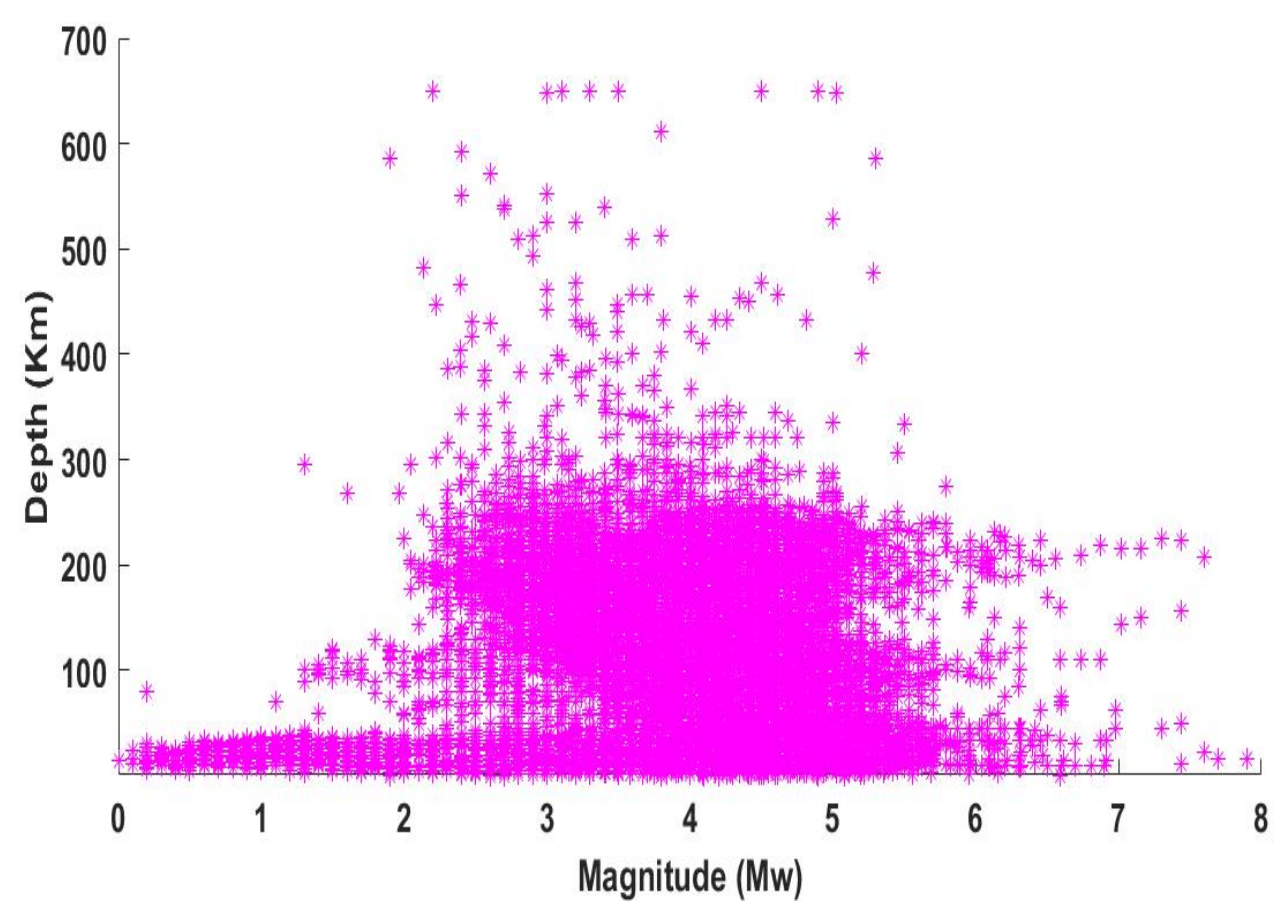

Fig. 2 Relationship between depth and magnitude of composite earthquake catalogue.

Hypocentral depth varied according to strain energy accumulated in the rock inside. Fault rupture is started at this point towards upper surface. Earthquakes can also be classified by the focal depth such as shallow earthquake $0-70 \mathrm{~km}, 70-300 \mathrm{~km}$ intermediate, greater depth than $300-700 \mathrm{~km}$ called deep earthquake (Naylor et al., 2009). Hypocentral depth and magnitude relation describes the earthquake ground variability and it gives an idea to estimate the crustal behavior (Mignan and Woessner, 2012). The depth is depending event of magnitude. The relation between magnitude and depth shows higher magnitude greater than 7 at shallow $20 \mathrm{~km}$ depth (Fig. 2). Saturation can be seen at different depth level in plot from magnitude 3.5 to 5.0 varied shallow to moderate depth. Only few seismic events can be observed beyond the depth from 400 to $600 \mathrm{~km}$. Moderate depth earthquakes can also be seen in magnitude depth relation. The seismicity rate depends upon the nature of tectonic environment as well as active fault system (Ogata, 1988). This saturation of earthquake events in particular depth at shallow or moderate level cannot be ignored. In this scenario active ground motion continuously observed in an earthquake prone area where earthquakes less than 3.5 magnitude are occurred several times in a day but they are not reported and useful for further observation.

\subsection{HISTOGRAM DISSIMILARITY AND EVENTS DISTRIBUTION}

Variation in large amount of data can be easily interpreted using statistical techniques and their relevant tools. The focal depth, magnitude and number of earthquakes are crossplotted in Figure 3. The correlation between these variables data of different column can be estimated by frequency distribution in specified range. In Figure $3 \mathrm{a}$ bar chart describes the magnitude ranges from 0 to 8 with frequency distribution of earthquakes. Each bin is a bar and each bar has 1000 interval and magnitude of earthquake is height of bar. Histogram is showing that earthquake with magnitude range from 3.5 to 4.5 occurred with almost 1000 times. It means fast seismicity rate between this magnitude range. Figure $3 b$ bar chart explained the seismicity distribution with respect to depth. Shallow seismic events can be seen at $0 \mathrm{~km}$ to $50 \mathrm{~km}$. The frequency of earthquake occurrence against number of years is demonstrated in Figure 3c. In last two decades an increasing trend of earthquake occurrence can be observed, which is due to increase in velocity of plate motion because of presence of numerous active fault system.

Figure $3 \mathrm{~d}$ demonstrates the frequency distribution between magnitude, depth and number of seismic events of shallow to intermediate depth. Very less events with depth $d \geq 250 \mathrm{~km}$ are found to be announced as deep earthquake. Majority of the events are observed with depth $\mathrm{d} \leq 50 \mathrm{~km}$. Continues crustal deformation is another cause to increase the seismicity.

Geographically, in all over the world, on $b$-value vast study has been done for regional and local level (Ben et al., 1980; Ahmed et al., 2016; Khan and Kumar, 2020). Different methods compute different 

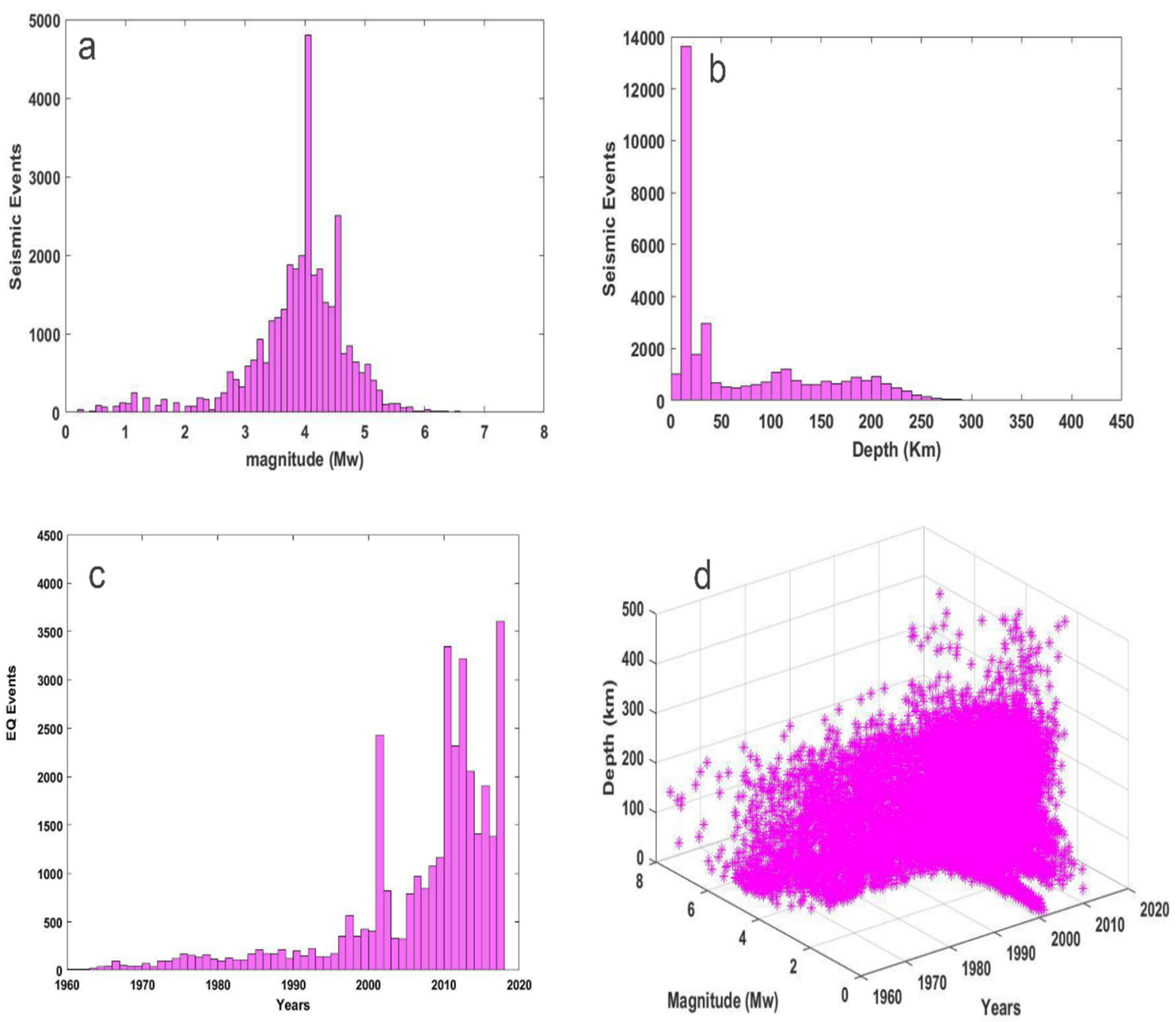

Fig. 3 a) Graph between earthquake magnitudes and seismic events, b) Graph between focal depth versus seismic events, c) Graph between years of occurrence of seismic events and number of seismic events, d) $3 \mathrm{D}$ graph represents the relationship between focal depth, magnitude and year of occurrence of seismic events.

$b$ - values for same seismotectonic zone, thus $b$-value estimation can be affected by declustering (Taroni and Akinci, 2021). Senartorski (2017) and Senartorski (2020) proposed $b$-value and earthquake asperity model which is based on the GR relation. Many researchers determine the $b$-value using least squares methods or maximum likelihood method (Aki, 1965; Bender, 1983; Main, 2000). According to Enescu and Ito (2003), frequency and magnitude relation is based on three main factors that influence the significant variation in periodically occurrence of earthquake per year. a) non homogeneity of material causes to increase the $b$-value (Mogi, 1962); b) higher the lithospheric pressure lowers the $b$-value (Wyss, 1973); c) increase the $b$-value due to increase the thermal gradient (Warren and Latham, 1970). Additionally, study of $b$-value is generally differentiating in two types of concentration, volume of crustal rock globally and tectonic environment in different state with diverse faulting. Moreover, $b$ value has inverse relation with stress accumulation inside crust same as effective stress decrease the $b$-value and lower the $b$-value may indicate that high stress (Gibowicz, 1973; Wyss, 1973). There is also a correlation with effective stress with magnitude and mainshocks (Kanamori, 1983). Therefore, frequency magnitude relation expresses the earthquake occurrence over the specific time period.

In this research article declustering process was applied on earthquake database to eliminate the dependent / duplicate events from catalogue in the study region. Secondly determine the magnitude of completeness of whole study region and compare it with individually determine years' wise magnitude of completeness. This enables us to check the variability of magnitude of completeness periodically over the time period. Furthermore, we will find the values of frequency magnitude relation parameters with their spatio-temporal mapping. 


\section{METHODOLOGY AND DATA SET}

Before declustering process a comprehensive cluster catalogue contained more than 30,000 events was prepared including epicenter location, time, magnitude, depth from 1960 to December 2018.This catalogue covers the whole Pakistan including Hindukush, the region in North, Iran block on the western side and Makran subduction zone (MSZ) in the Southwestern Pakistan as well as coastline area of Arabian sea in the southern Pakistan (Kazmi and Jan, 1997). The region geographically restricted by latitude $20^{\circ}-40^{\circ} \mathrm{N}$ and longitude $60^{\circ}-80^{\circ} \mathrm{E}$.

All approaches for computing declustering consist of time and distance-space window. A Matlab based program called ZMAP, a graphical user interface (GUI) tool has been utilized for analyze of the seismicity and associated parameters (Wiemer, 2000). ZMAP widely used by seismologists and geophysicists for earthquake distribution and their fault parameters as well. This tool consists numerous declustering methods and a lot of proposed procedure to determine $a$ and $b$-value from GR frequency magnitude relation. However, declustering steps are broadly used to reorganize the earthquake catalogue without duplication, redundant and dependent events with out. All above mentioned procedures based are on the accessibility of source codes

\subsection{WINDOW METHOD FOR DECLUSTERING}

The clustering of earthquake data was used by Aki (1956), Aki (1965) and Knopoff (1964) to determine that either it is Poissonian or not? Initial study is inferring that earthquake catalogue is not accurate for Poisson distribution. They tried to decluster the seismic event using different algorithm excluding aftershocks and foreshocks. Gardner and Knopoff (1974) designed a window based method for declustering in which they proposed that aftershocks located as succeeding shocks within specified distance and particular time interval. Same as in the case of foreshocks, succeeding foreshocks generate a large magnitude earthquake that will be treated as large aftershocks. If the catalogue contained the high rate of seismicity such as a comprehensive earthquake catalogue, it is essential to decluster them. According to Knopoff and Gardner (1972) and Gardner and Knopoff (1974) window size is a function of time and distance slots. The declustering method elaborates the distance and time window designed by Gardener and Knopoff (1974). They described that an event is said to be an aftershock if a large earthquake $M=6.5$ (say) is reoccurred within next 790 days with nearly same magnitude with epicenter $61 \mathrm{~km}$ then this may be declared as an aftershock. They present this method in the form of mathematical expression given below

$d=10^{0.1238 * M+0.983[\mathrm{~km}]}$

$t=\left\{\begin{array}{l}10^{0.032 * M+2.7389,} \\ 10^{0.5409 * M-0.547},\end{array}\right.$ else if $M \geq 6.5$ [days]

$$
\begin{aligned}
& d=e^{1.77+(0.037+1.02 * M)^{2}}(\mathrm{~km}), \\
& t=\left\{\begin{array}{c}
\left.\left|e^{-3.95+(0.62+17.32 * M)^{2}}\right|\right\} \text { if } \quad M \geq 6.5 \text { else } \\
10^{2.8+0.024 * M}
\end{array}\right\} \text { if } \\
& d=e^{-1.024+0.804 * M}[\mathrm{~km}] \\
& t=e^{-2.87+1.235 * M}[\text { days }]
\end{aligned}
$$

where $d$ represents distance window and $M$ is the moment magnitude. The auxiliary parameters can be derived by the following expressions (Gardner and Knopoff, 1974) and $t$ is the time space window. The integrate classification of background earthquakes is the critical objective of declustering which mean earthquake data base are independent of all forgoing seismic events.

\subsection{FREQUENCY MAGNITUDE RELATION (GR LAW) AND MAGNITUDE OF COMPLETENESS (MC)}

A well-known relation between earthquake occurrence and frequency of magnitude is proposed by Gutenberg-Richter (1935) is used for rate of earthquake occurrence per year i. e.

$\log _{10}(N)=a-b M$

$N=(10)^{a-b M}$

Here $M$ as $M_{w}$ (moment magnitude), $N$ is accumulated numbers of earthquake above the magnitude $M_{w}$. Surface wave magnitude can also be used instead of moment magnitude for observance of frequency magnitude relation. This relationship is extensively utilized to estimate the earthquake occurrence in specific time period and it is a probability based function which depends on the magnitude of earthquake in any region (Rehman et al., 2015).

\subsection{MAGNITUDE OF COMPLETENESS (MC)}

Some historical earthquake events and those events which are based on ancient observation were also included in the catalogue. After installing the seismometer on various sites in Pakistan, it is easy to arrange earthquake catalogue. However, other sources were also helpful to organized composite complete catalogue. Seismic attenuation and peak ground acceleration are depending on subsurface lithology and earthquake source characteristics. Seismic hazard analysis is one of the best tool to investigate the $g$ value for single site investigation of multisite which is based on earthquake intensity. So, it is needful to understand the importance of earthquake catalogue and magnitude of completeness $(M c)$ before computing the hazard value and response spectra (Stepp, 1972). In seismic hazard analysis, $M c$ has significant and unique value in catalogue for any region. There are a lot of methods to find the $M c$ from seismic data base like maximum curvature, maximum likelihood method as mention in ZMAP. Maximum likelihood method was used to evaluate the magnitude of completeness. Maximum likelihood method was used which is a simple technique. Magnitude of 

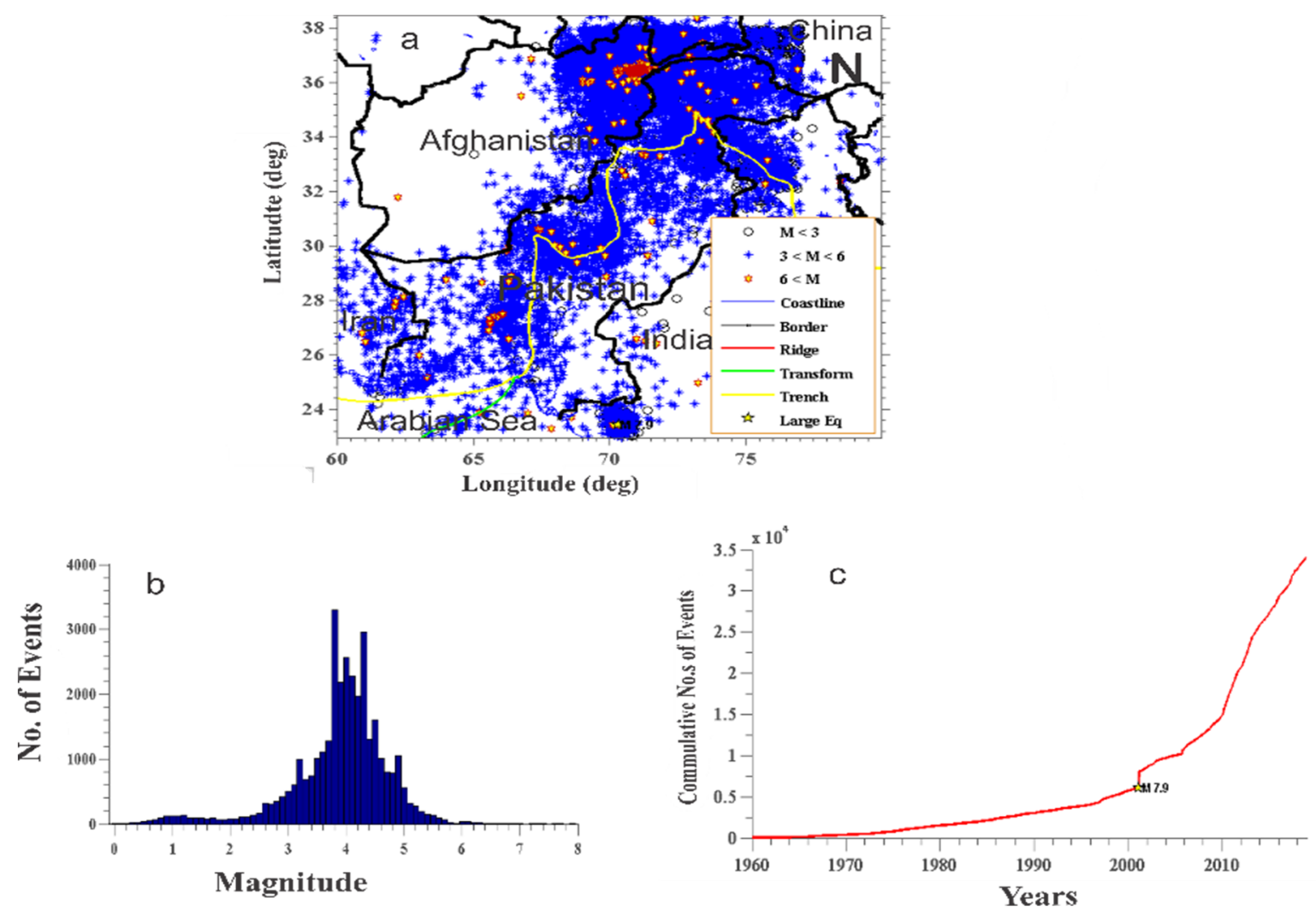

Fig. 4 a) Seismotectonic map with plate boundaries of the study area. Blue line shows the plate boundaries, green line for transform boundary and black line is the border of geographic boundary, b) Histogram variation between number of earthquakes and magnitude, c) Cumulative number of earthquakes with respect to time period (year).

completeness $(M c)$ satisfies the GR law of goodness using best fit method or maximum likelihood method defined by Wiemer and Wyss (2000, 2002). If the value of $M c$ is too high, then data was under sampling by removal of unwanted data and if the value is too low and approaches to negative this represents the inaccuracy among the seismic parameters and during data collection (Mignan and Woessner, 2012). Moreover, the completeness analysis on whole earthquake catalogue or various magnitude intervals provides the impartial approximation of the previous seismicity (Khan and Kumar, 2018). This $M c$ value can be used further for design the high rise building or dam site construction in seismic hazard analysis as well as response spectra.

\section{RESULTS AND DISCUSSION}

Elimination process of foreshocks, aftershocks from earthquake catalogue is the basic step to check consistency / authenticity of earthquake catalogue. The catalogue may or may not be homogenous with respect to type of magnitude or focal depth. If the data is well recorded and best fitted, then the outcome is understandable and easily interpreted. Pakistan earthquake data base arrange from National and some International seismic network stations database. Moment magnitude was utilized for homogeneously distribution of earthquake. Figure 4 represents the initial presentation of earthquake catalogue for study region in Pakistan. In Figure 4a seismotectonic map of Pakistan and its surrounding region is showing the seismicity and tectonic plate movement in and around Pakistan. Seismicity epicenter locations scatter in black color spots. The plate boundaries are in blue color where yellow line showing the oceanic plate passes coastline near subduction zone in Makran. This continues collision is the roots of seismicity rate in different region of Pakistan. In Figure $4 \mathrm{~b}$ histogram displays the magnitude distribution and number of earthquakes. Maximum number of events is of the magnitude 3.5. In Figure 4c cumulative number of earthquakes frequency is showing an increasing trend in the last 2 decades which is horrible. It can be seen that in 1960 to 1980 the earthquake intensity is not much more comparatively last two decades. Global warming, active tectonic regime and geothermal gradient or subsurface temperature are the possible factors to increasing the seismicity rate (Usman and Zafar, 2010).

\subsection{DECLUSTERING PROCESS (TIME AND DISTANCE WINDOW)}

The declustering process defined by Knopoff and Gardner (1974) was used to draw mapping of 

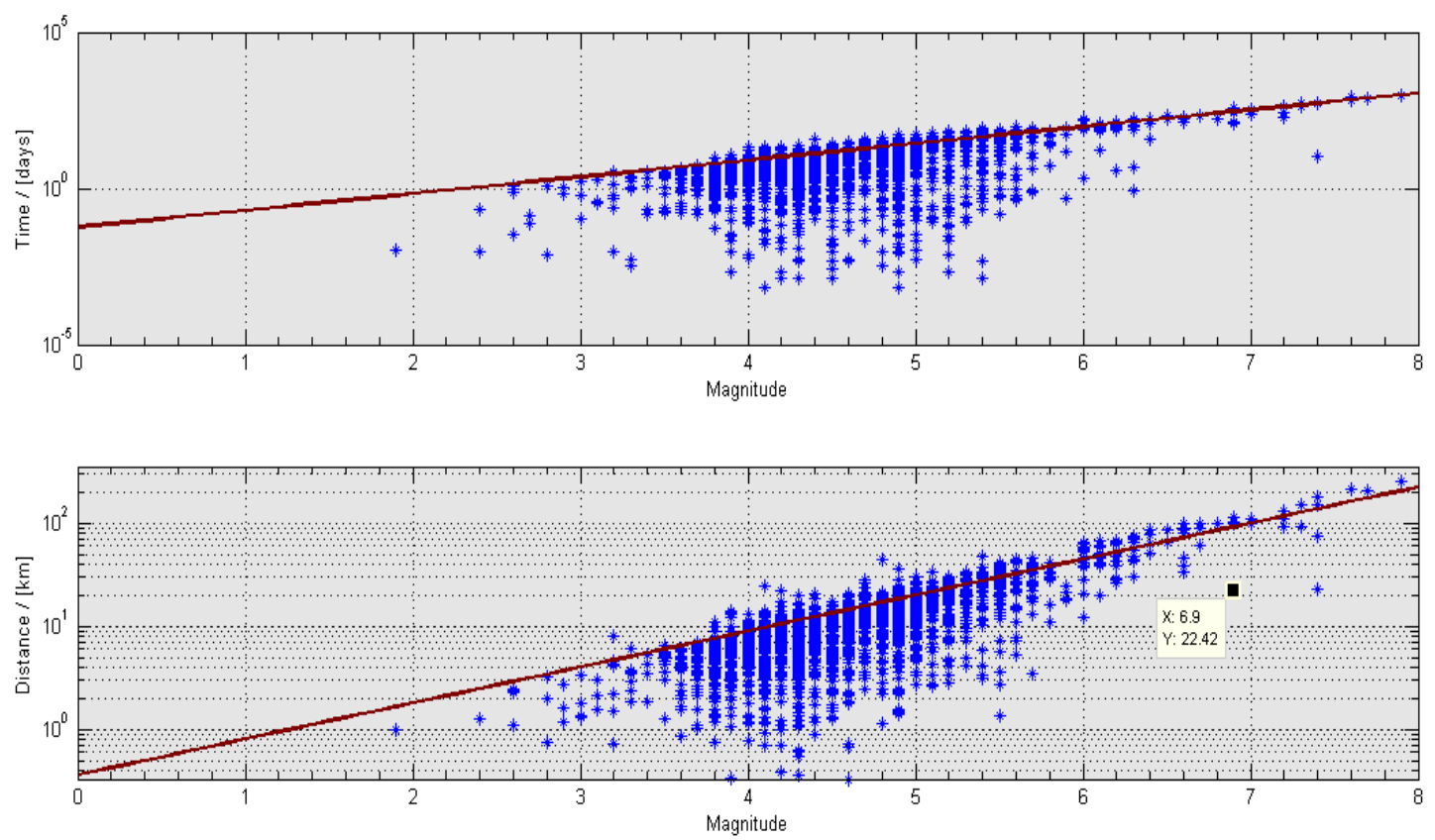

Fig. 5 Time and distance space window for declustered earthquake catalogue 1960-2019.

clustered and declustered events. Declustering is based on magnitude - distance time window. So ZMAP separates it into two parts at same time such as magnitude distance and magnitude time (period) window. Any seismic event which set to this two window will be the foreshocks and aftershocks (under brown line). According to Figure 5 two windows were drawn to measure the time and distance table with respect to magnitude for aftershocks. In Table 1 number of aftershocks were identified. Correspondingly, if the event of $M=6.5$ happened and if earthquake of this magnitude again happened in epicentral distance $89 \mathrm{~km}$ in coming 173 days then this earthquake declared as an aftershock of that earthquake. The same process is continuing till whole catalogue will be scrutinized. The declustering found 2714 clusters of earthquake. In map window blue dots shows that these are declustered events which have specific time and distance as per algorithm.

Three main classes have been defined in real seismicity, i.e. mainshocks, aftershocks and foreshocks. The correlation between large seismic events has been confirmed, but the earthquake occurrence sequence between them is not sure on the basis of similarities with each other. Therefore, numerical values of aftershocks and foreshocks have countered as given in Table 1 supported with time and distance window.

After identifying the declustered events from earthquake catalogue, a map was drawn for declustered events specified by magenta pluses in color in Figure 6. They are also called mainshocks of remaining earthquake catalogue.

Magnitude of completeness obtained from Wiemer $(2000 ; 2005)$ which is based on GR frequency
Table 1 Time and space window tabular for identification of aftershocks.

\begin{tabular}{ccc}
\hline $\mathrm{M}$ & $\mathrm{d}(\mathrm{Km})$ & $\mathrm{t}($ days $)$ \\
\hline 2.5 & 3 & 2 \\
3.0 & 4.1 & 3 \\
3.5 & 6 & 5 \\
4.0 & 10 & 23 \\
4.5 & 18 & 40 \\
5.0 & 30 & 60 \\
5.5 & 44 & 95 \\
6.0 & 61 & 147 \\
6.5 & 89 & 173 \\
7.0 & 100 & 322 \\
7.5 & 149 & 680 \\
8.0 & 254 & 980 \\
\hline
\end{tabular}

magnitude relation (FMR) as defined in Eq. (5). Higher magnitude value of $M c$ shows that catalogue sample is under weight or unwanted repeated data and $M c$ is very low as approaches to negative which represents the inaccuracy among the seismic parameters and some error must be happened during data collection (Mignan and Woessner, 2012). However, in this study, our samples are neither overweight nor underweight. A significant value of $M c$ was obtained for study region. The maximum likelihood method was used for the period 1960-2019 to determine the $M c$ was 3.8 with $a=5.54$ and $b$-value $0.78+/-0.004$ (Fig. 7). This $M c$ value varied in different decades due to change in number of earthquakes in each decade. Cross plotting between numbers of earthquakes over the specific period effect the magnitude of completeness. Taroni and Akinci (2021) also explained the $M c$ variation depends on 


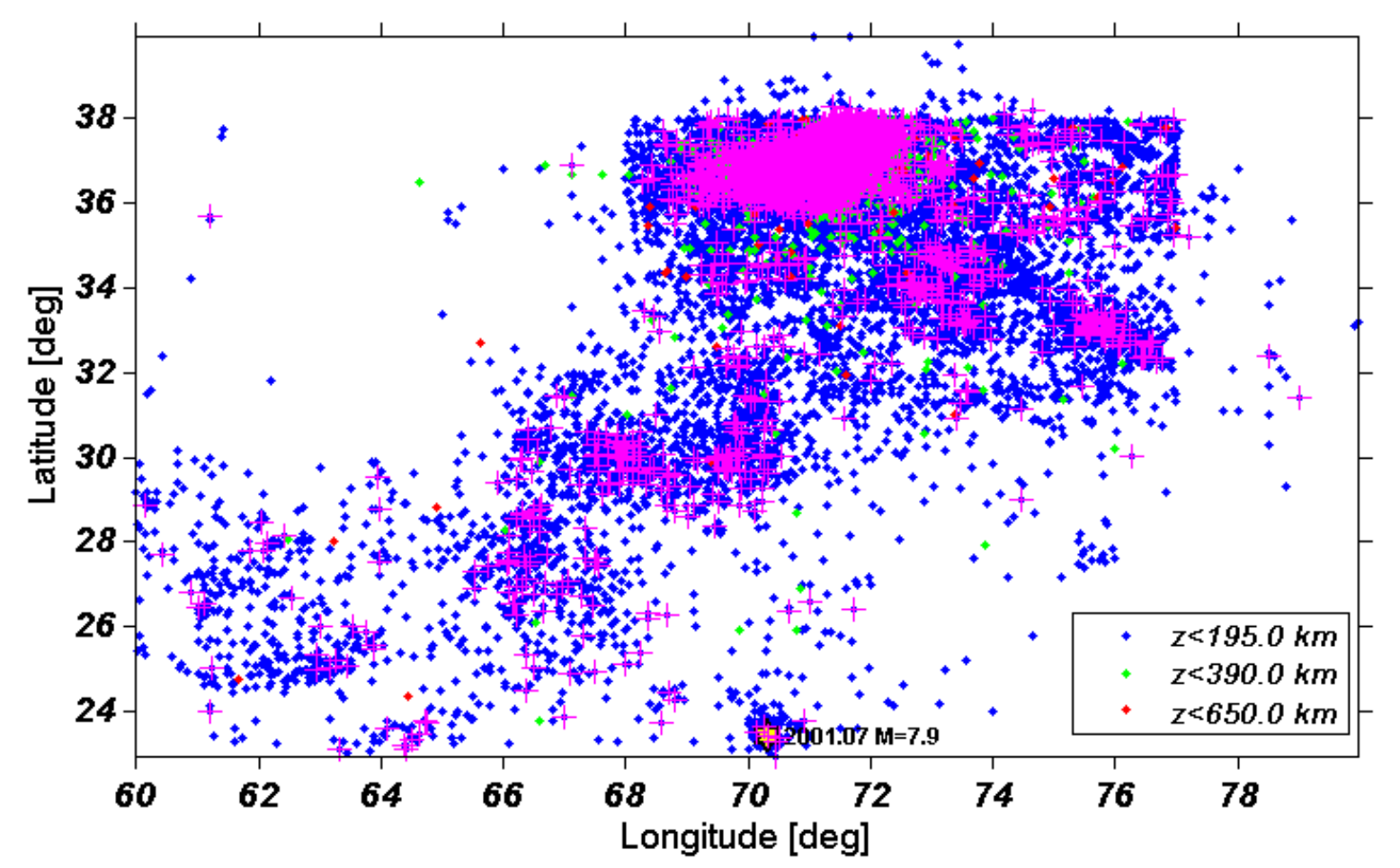

Fig. 6 Remaining clustered events (mainshocks) as pluses sign displaying in magenta color using window method.

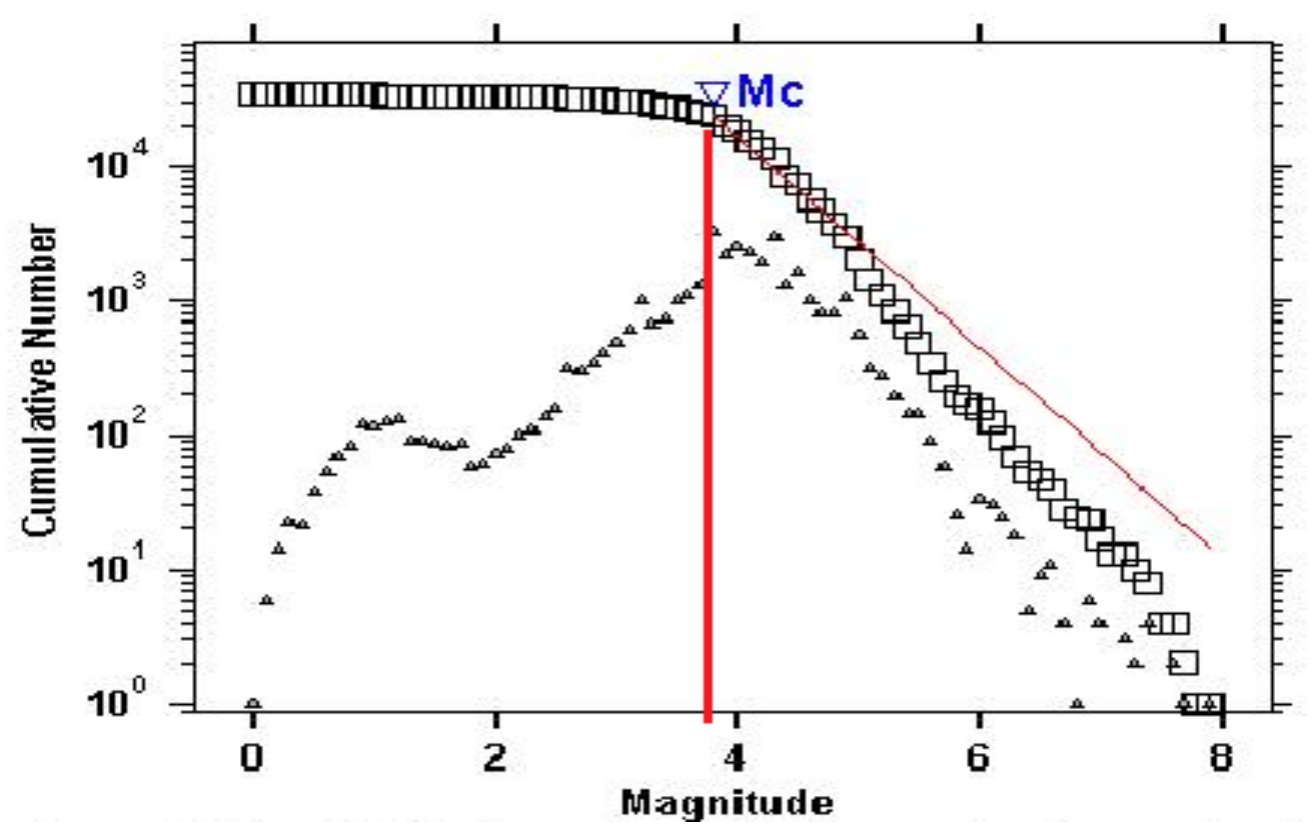

b-value $=0.78+/-0.004$, a value $=7.34$, a value (annual $)=5.57$

Magnitude of Completeness $=3.8$

Maximum Likeliheod Solution

Fig. 7 Maximum likelihood solution of magnitude of completeness $(M c)$ and accumulated numbers of earthquake. 

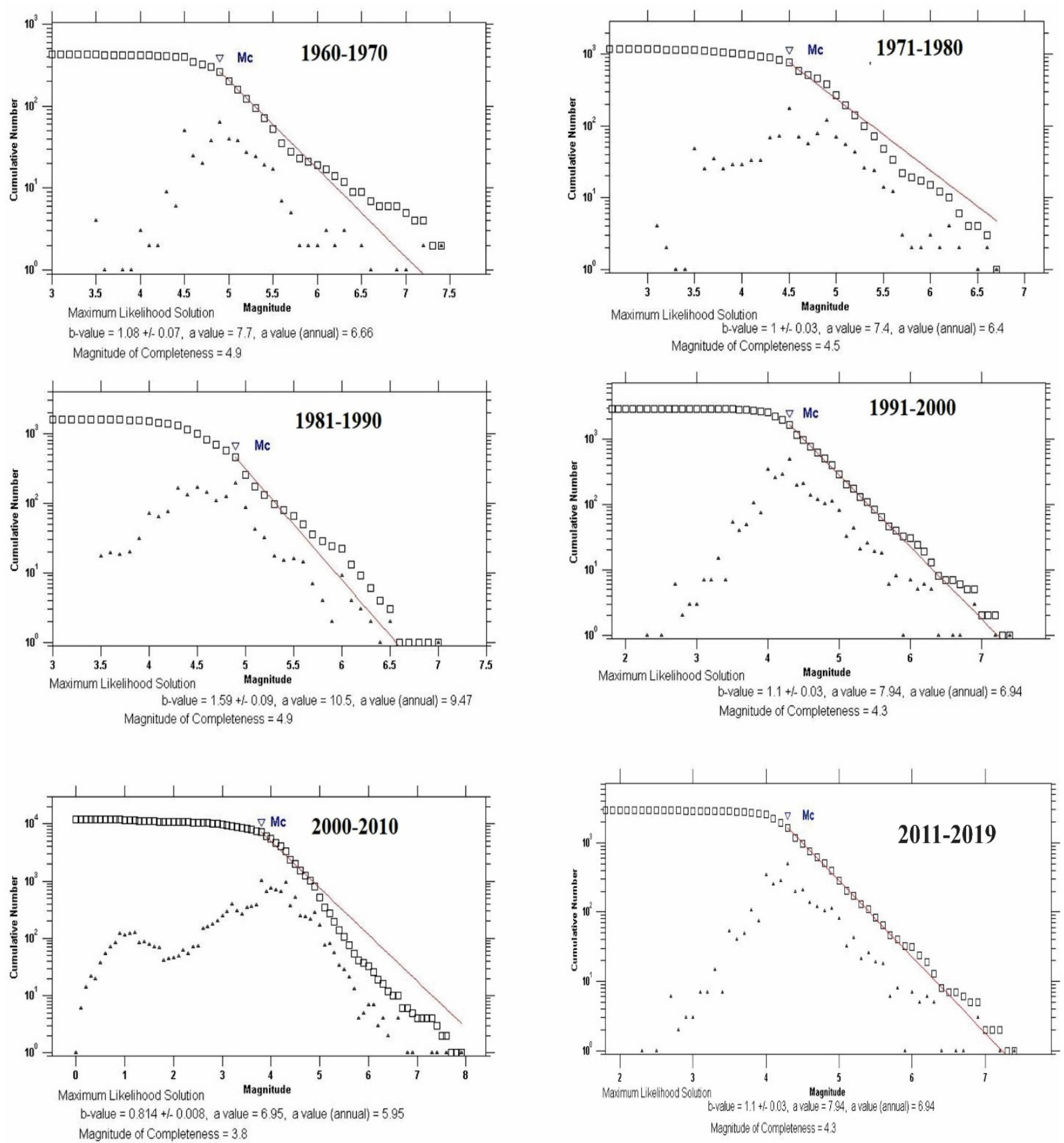

Fig. 8 Crossplot between earthquake magnitude and number of earthquakes for determination of magnitude of completeness for each ten years cycle in the study area.

time period or rate of occurrence of seismic events. For example, time window between 1960 and 1970, $M c$ was 4.9 and for period 2000 to 2010 the $M c$ was 3.8, however the $M c$ varied within 4.0 to 4.9 in all time based category. The last decade 2011-2019 and 1999-2000, Mc was 4.3 whereas 1960-1970 it was 4.9 as mentioned above. The seismic events affect the $M c$ and this change may vary periodically. The completeness of magnitude for different interval of time indicates the impartial approximation of previous recorded seismicity.

According to the Woessner and Wiemer (2005) Maximum curvature method, provision of +0.2 factor can be added in the existing calculated magnitude of completeness w.r.t. time period to attain the true value of $M c$. This is an addition to known $M c$ for the earthquake composite catalogue which can also be correlate with synthetic catalogue. All the factors are added into computed $M c$ values given in Table. 2

\subsection{SPATIO-TEMPORAL MAPPING OF a AND b- VALUES IN DIFFERENT TECTONIC REGIMES}

Frequency magnitude relation (FMD) obeys the power law of linear expression and best fit for small magnitude. This best fit model based on recording network station efficiency for store magnitude lower 
Table 2 Conversion factor of $M c$ using max curvature method into computed $M c$.

\begin{tabular}{llcc}
\hline Period / Years & Computed $M c$ & Max Curvature Factor & Max. Curve. $(M c)$ \\
\hline $1960-1970$ & 4.9 & & 5.1 \\
$1971-1980$ & 4.5 & 0.2 & 4.7 \\
$1981-1990$ & 4.9 & & 5.1 \\
$1999-2000$ & 4.3 & & 4.5 \\
$2000-2010$ & 3.8 & & 4.0 \\
$2011-2019$ & 4.3 & & 4.5 \\
\hline
\end{tabular}
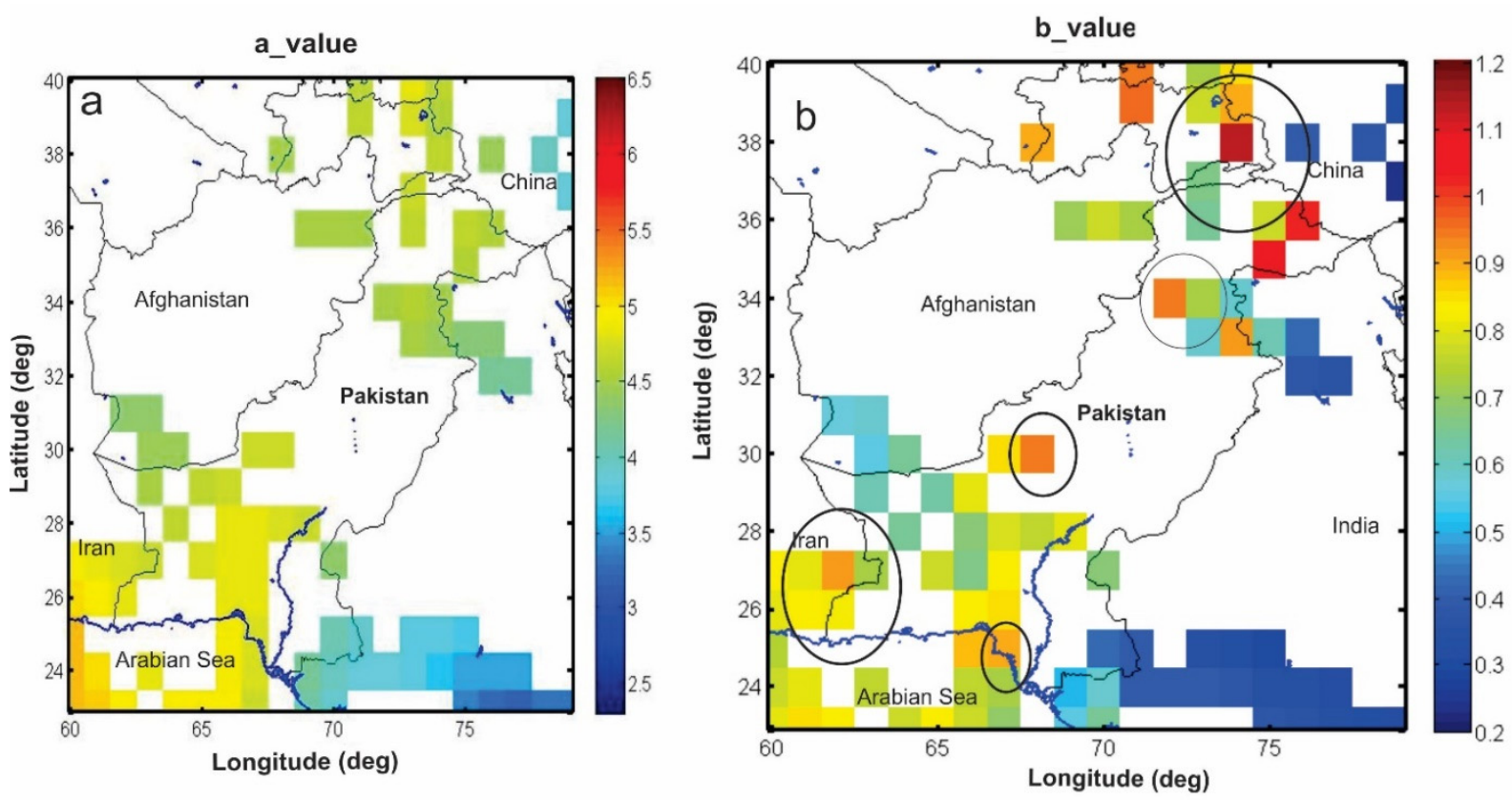

Fig. 9 Spatio-temporal mapping of $a$ and $b$-value for different regions of Pakistan.

than $M c$. To find the $b$-value and $a$-value is another objective in the study of seismicity analysis. Mostly $a$-value used to define the seismicity rate and $b$-value for regime of stresses and tectonic environment. These parameters related to the seismicity behavior and their factors. Using ZMAP spatial and temporal mapping of $a$ and $b$-value was drawn in Figure 9 for variability of rate of change of seismicity and slope of the region. As the $b$-value increases the vulnerability also increases due to steepness and gradient of rocks or hill. The $b$-value is higher showing the intense seismotectonic environment. Geographically, on Pak-Iran border the $b$-value is higher, approached to 1 due to Iranian block on Eurasian plate. This southern part consists of Eurasian and Arabian plate collision. Intense seismicity can be observed here this causes to increases the rate of earthquake occurrence. Seismicity rate " $a$ " is moderate value from 4.5 to 5 . The productivity rate " $a$ " value shows the seismicity rate is higher in the region. For considering the $b$-value to northward, $b$-values increase from 0.7 to 0.8 . In northern side maximum $b$-value is attained due to collision rate of tectonic plates varied from 1 to 1.1 . This $b$-value indicates that this region is highly prone to earthquakes. In fact, at this location there are many fault systems produced by convergent plate boundary.
Mostly they are reverse faults generated due to over thrusting. Different zones have different $a$ and $b$-values and this depends on tectonically activeness of the region. Only one thing is also considerable that what behavior of $b$-value was. Variation in $b$-value with different time span is showing less than 1.0 particular in 2000 - 2010 earthquake catalogue. The remaining all windows of time period $b$-value has an increasing trend towards 1.0 with time and region. Faulting style also effects the variation in $b$-values. Convergent and divergent regime may also effect the size distribution of earthquake.

\section{CONCLUSIONS}

Pakistan tectonically rides on two continental plates in the northern and western region whereas in the southern part subduction process still carries on between the Arabian and Indian plates. Due this motion many fault and fold systems have been still generating. These plates' boundaries are main sources of earthquake triggering and activation of ground movement process. This motion has been continually observed from installed seismic station for development of earthquake forecasting and prediction analysis. To evaluate this phenomenon, a complete and well recorded earthquake catalogue is required. 
A preliminary and earliest exertion for declustering of seismicity database was only done for defining Poisson or Non-Poisson in statistical manners. Moreover, if the seismic events are arbitrary then make sure that the catalogue is not Poisson and there is no chance to predict any single event of reoccurrence under specific time period and if there is some connection between an event with another than there can must be relation. A Matlab based program was used to truncate foreshock and aftershocks in the term of distance - magnitude and time - magnitude space window. This study has done to demarcate the numbers of mainshock. The foreshocks and aftershocks from earthquake catalogue were removed using Matlab based program (Gardener and Knopoff, 1974). From this method tabulated values are obtained that show if the earthquake of $M=3.5$ comes and same magnitude earthquake come again in next 5 days within the epicentral distance of $6 \mathrm{~km}$ then this will be counted as an aftershock of preceding large earthquake. Correspondingly, if the event of $M=6.5$ happened and if the earthquake of this magnitude again happened with in epicentral distance of $89 \mathrm{~km}$ in coming 173 days then this earthquake will have to reckoned as an aftershock. The declustering found 2714 clusters of earthquake in which blue dots show that these are declustered events after removal over the specific time and distance as per algorithm. Magnitude of completeness $M c$ was also obtained through maximum likelihood solution in which all magnitude above $M c=3.8, a=7.34$ and $b$-value $=0.78(+-0.04)$ is well established and are free from any duplicate and repeated event from catalogue. Gutenberg and Richter frequency - magnitude relation is mostly used in earthquake predecessor and earthquake hazard assessment in probability distribution. The spatial and temporal mapping of " $a$ and $b$ " values was draw in which rate of productivity and slop of line representing the seismotectonic level of region. Calculated $b$-value for northern Pakistan is higher as $\sim 1.0$ to 1.1 and in eastern Pakistan this become lower to $\sim 0.8-0.9$ and in the southern Pakistan $\sim 0.4$, whereas in Pak- Iran border this $b$ - value increases as approached to 1.0. This shows that $b$-value approached to $\sim 1.0$ varied from region to region. The variation in $b$-value depends on the inside stresses and tectonic setting of any region. Therefore, higher value of " $a$ " increases the seismicity rate / productivity of the region. In overall setting, higher $b$-value in any specific part may lead to important key to future earthquake. It will helpful in proposing the earthquake forecast model using composite earthquake data which is based on statistical analysis and $b$-value for some particular region can easily be detectable.

\section{REFERENCES}

Aki, K.: 1956, Some problems in statistical seismology. Zisin, 8, 4, 205-228.

DOI: $10.4294 /$ zisin1948.8.4_205
Aki, K.: 1965, Maximum likelihood estimate of $b$ in the formula $\log \mathrm{N}=\mathrm{a}-\mathrm{bM}$ and its confidence limits. Bull. Earthq. Res. Inst., Tokyo Univ, 43, 237-239. DOI: $10.1007 / \mathrm{BF} 00881745$

Ali, M.S.: 2016, Statistical analysis of seismicity in Egypt and its surroundings. Arab. J. Geosci., 9, 52. DOI: 10.1007/s12517-015-2079-x

Bender, B.: 1983, Maximum likelihood estimation of $b$ values for magnitude-grouped data. Bull. Seismol. Soc. Am., 73, 831-851. DOI: $10.1785 / \mathrm{BSSA} 0730030831$

Baiesi, M. and Paczuski, M.: 2004, Scale free network of earthquakes and aftershocks. Phys. Rev., E, 69, 66106. DOI: 10.1103/PhysRevE.69

Braunmiller, J., Deichmann, N., Giardini, D. and Wiemer, S.: 2005, Homogenous moment magnitude calibration in Switzerland. Bull. Seismol. Soc. Am., 95, 1, 58-74. DOI: $10.1785 / 0120030245$

Console, R., Jackson, D.D. and Kagan, Y.Y.: 2010, Using the ETAS model for catalog declustering and seismic background assessment. Pure Appl. Geophys., 167, 819-830. DOI: $10.1007 / \mathrm{s} 00024-010-0065-5$

Frohlich, C. and Davis, S.: 1985, Identification of aftershocks of deep earthquakes by a new ratios method. Geophys. Res. Lett., 12, 10, 713-716. DOI: $10.1029 /$ GL012i010p00713

Gardner, J.K. and Knopoff, L.: 1974, Is the sequence of earthquakes in southern California, with aftershocks removed Poissonian? Bull. Seismol. Soc. Am., 64, 1363-1367. DOI: 10.1785/BSSA0640051363

Gibowicz, S.J.: 1973, Variation of the frequency-magnitude relation during earthquake sequences in New Zealand. Bull. Seismol. Soc. Am., 63, 517-528.

DOI: $10.1785 /$ BSSA0630020517

Grunthal, G., Wahlstrom, R. and Stromeyer, D.: 2009, The unified catalogue of earthquakes in entral, northern, and northwestern (CENEC) - Updated and expanded to the last millennium. J. Seismol., 13, 517-541. DOI: $10.1007 / \mathrm{s} 10950-008-9144-9$

Gupta, S., Kumar, S., Wason, H.R. and Das, R.: 2012, Statistical analysis of completeness of earthquake data around Dehradun city and its implication of seismicity evaluation. 15 WCEE, Lisboa.

Gutenberg, B.: 1945a, Amplitudes of P, PP and magnitudes of shallow earthquakes. Bull. Seismol. Soc. Am., 35, 57-69. DOI: 10.1785/BSSA0350020057

Gutenberg, B.: 1945b, Magnitude determination for deepfocus earthquakes. Bull. Seismol. Soc. Am., 35, $117-$ 130. DOI: 1 0.1785/BSSA0350030117

Gutenberg, B. and Richter, C.F.: 1954, Seismicity of the Earth and associated phenomena. $2^{\text {nd }}$ ed., Princeton University Press.

DOI: $10.1111 / \mathrm{j} .2153-3490.1950 . t b 00313 . x$

Gutenberg, B. and Richter, C.F.: 1956a, Magnitude and energy earthquakes. Ann. Geophys., 9, 1-15. DOI: $10.4401 /$ ag-5590

Gutenberg, B. and Richter, C.F.: 1956b, Earthquakes magnitude, intensity, energy and acceleration. Bull. Seismol. Soc. Am., 46, 105-145. DOI: $10.1785 / \mathrm{BSSA} 0460020105$

Kanamori, H.: 1983, Magnitude scale and quantification of earthquakes. Tectonophysics, 93, 185-199. DOI: $10.1016 / 0040-1951(83) 90273-1$

Kazmi, A.H. and Jan, M.Q.: 1997, Geology and tectonics of Pakistan. Graphics Publishers, Karachi. 
Khan, M.M. and Kumar, G.K.: 2018, Statistical completeness analysis of seismic data. J. Geol. Soc. India, 19, 749-753. DOI: 10.1007/s12594-018-0934-6

Khurram, S., Khalid, P., Qureshi, J. and Zia, Ud.D.: 2021, Assessment of seismic hazard of roller compacted concrete dam site in Gilgit-Baltistan of northern Pakistan. Earthq. Eng. Eng. Vib., 20, 621-630. DOI: $10.1007 / \mathrm{s} 11803-021-2042-7$

Main, I.G.: 2000, Apparent breaks in scaling in the earthquake cumulative frequency-magnitude distribution: Factor artifact? Bull. Seismol. Soc. Am., 90, 86-97. DOI: 10.1785/0119990086

Mignan, A. and Woessner, J.: 2012, Estimating the magnitude of completeness for earthquake catalogs. Community Online Resource for Statistical Seismicity Analysis. DOI: 10.5078/corssa-00180805

Naylor, M., Main, I.G. and Touati, S.: 2009, Quantifying uncertainty in mean earthquake inter-event times for a finite sample. J. Geophys. Res., 114, B01316. DOI: $10.1029 / 2008 J B 005870$

Ogata, Y.: 1988, Statistical models for earthquakes occurrences and residual analysis for point processes. J. Am. Stat. Assoc., 83, 401, 9-27. DOI: $10.2307 / 2288914$

Pisarenko, F.V. and Rodkin, V.M.: 2019, Declustering of the seismicity flow. Statistical analysis. Phys. Solid Earth, $55,5,773-745$. DOI: $10.31857 / \mathrm{S} 0002-33372019538-52$

Ray, S., Alam, Md.J.B., Haque, M., Das, K.S., Tanmoy, B.B. and Hasan, N.Md.: 2019, A study on b value and investigation of seismic hazard in Sylhet seismic region, Bangladesh using Gumbel's extreme value distribution method. SN Appl. Sci., 1, 435. DOI: $10.1007 / \mathrm{s} 42452-019-0442-3$

Reasenberg, P.: 1985, Second-order moment of central California seismicity, 1969-82. J. Geophys. Res., Solid Earth, 90, B7, 5479-5495. DOI: 10.1029/JB090IB07P05479

Rehman, K., Ali, A., Ahmed, S., Ali, W., Ali, A. and Younas, K.: 2015, Spation-temproal variation of $b$ value in and around the north Pakistan. J. Earth Syst. Sci., 124, 7, 1445-1456.

DOI: $10.1007 / \mathrm{s} 12040-015-0625-2$

Richter, C.F.: 1935, An instrumental earthquake magnitude scale. Bull. Seismol. Soc. Am., 25, 1, 1-32. https://resolver.caltech.edu

Seeber, L., Armbruster, J. and Farhatullah, S.: 1980, Seismic activity at Tarbela dam site and surrounding region. Geol. Bull. Univ. Peshawar ,13, 169-191.

Senartorski, P.: 2017, Effect of slip-area scaling on the earthquake frequency-magnitude relationship. Phys. Earth Planet. Int., 267, 41-52. DOI: 10.1016/j.pepi.2017.04.004

Senartorski, P.: 2020, Gutenberg-Richter's b value and earthquake asperity models. Pure Appl. Geophys., 177, 1891-1905. DOI: 10.1007/s00024-019-02385-z

Stepp, J.C.: 1972, Analysis of completeness of the earthquake sample in the Puget sound area and its effect on statistical estimate of earthquake hazard. Proc. International Conference on Micro Zonation, Seattle, 897-910.
Taroni, M. and Akinci, A.: 2021, Good practices in PSHA, Declustering, $\mathrm{b}$ value estimation, foreshocks and aftershocks. A case study in Italy. Geophys. J. Int., 224, 1174-1187. DOI: 10.1093/gji/ggaa462

Uhrhammer, R.: 1986, Characteristics of northern and southern California seismicity. Earthquake Notes, 57, $1,21 \mathrm{pp}$.

Usman, M. and Zafar, M.: 2010, Effects of temperature increase on earthquake frequency and depth in Northern Pakistan. International Conference on Biology, Environment and Chemistry. IPCBEE, 1.1, 2011, IACSIT Press, Singapore.

Van Stiphout, T., Zhuang, T.J. and Marsan, D.: 2012, Seismicity declustering. Community online Resource for Statistical Analysis. DOI: 10.5078/CORSSA-52382934

Warren, N.W. and Latham, G.V.: 1970, An experimental study of thermally induced micro fracturing and its relation to volcanic seismicity. J. Geophys. Res., 75. 4455-4464. DOI: 10.1029/jb075i023p04455

Wiemer, S.: 2001, A software package to analyze seismicity. ZMAP Seismol. Res. Lett., 72, 373-382. DOI: $10.1785 / \mathrm{gssrl} .72 .3 .373$

Wiemer, S. and Wyss, M.: 2000, Minimum magnitude of complete reporting in earthquake catalogs: example from Alaska, the Western United States and Japan. Bull. Seismol. Soc. Am., 90, 4, 856-869. DOI: 10.1785/0119990114

Wiemer, S. and Wyss, M.: 2002, Mapping spatial variability of the frequency-magnitude distribution of earthquakes. Adv. Geophys., 45, 259-302. DOI: $10.1016 / \mathrm{S} 0065-2687(02) 80007-3$

Woessner, J. and Wiemer, S.: 2005, Assessing the quality of earthquake catalogs. estimating the magnitude of completeness and its uncertainty. Bull. Seismol. Soc. Am., 9, 5, 684-698. DOI: 10.1785/0120040007

Wyss, M.: 1973, Towards a physical understanding of the earthquake frequency distribution. Geophys. J.R. Astron. Soc., 31, 341-359. DOI: 10.1111/j.1365246X.1973.tb06506.x

Zaliapin, I., Gabrielov, A., Keilis-Borok, V. and Wong, H..: 2008, Clustering analysis of seismicity and aftershock identification. Phys. Rev. Lett., 101, 1, 22-23. DOI: 10.1103/PhysRevLett.101.018501 